\title{
We were in one place, and the ethics committee in another: Experiences of going through the research ethics application process
}

\author{
Rob Brindley $\mathbb{D}^{\mathrm{D}}$, Lizette Nolte and Pieter W Nel
}

\begin{abstract}
This study aimed to explore postgraduate students' lived experiences of managing research ethics committee processes. Whilst there is a wide range of research that explores ethics principles/guidance and committee perspectives upon research ethics processes, there is a lack of research into applicant experiences of these processes. Thus, interpretative phenomenological analysis (IPA) was utilised to explore the lived experiences and personal meaning-making of seven doctoral-level students participating in clinical psychology training. Three main themes emerged from participants' accounts: (I) The emotional intensity and personal impact of the ethics process; (2) responses to and ways of managing the ethics process and (3) challenges within the ethics process. The results of this study highlight the importance of recognising the impact of the relationships between research students, courses and research ethics committees upon applicants' progress through the research ethics process. In particular, an unhelpful 'them and us' dynamic may be maintained by misunderstandings about each other's roles, uncertainty and stereotyping, amongst other factors. Potential ways to change this dynamic and to improve the research ethics process are explored.
\end{abstract}

\section{Keywords}

Research ethics, post-graduate research, clinical psychology

\section{Introduction}

Research skills are a key requirement of clinical training and practice for a range of physical and mental health professionals. In the UK, a significant proportion of these trainings taking place at post-graduate level which requires trainees to undertake an independent piece of research. ${ }^{1}$ Such projects are required to address an aspect of clinical practice, and therefore the majority of projects require some form of ethical approval from either the National Health Service (NHS) or university organisations. ${ }^{2}$ Within doctoral level clinical psychology training, the guidance for training course accreditation ${ }^{2}$ states specifically that by the end of their training, trainees should have developed "the skills, knowledge and values to conduct research that enables the profession to develop its knowledge base and to monitor and improve the effectiveness of its work" (BPS, ${ }^{2}$ p. 16). As part of their three-year doctorate, trainees are expected to complete a substantial research thesis representing a distinct and unique contribution to the practice of the profession. ${ }^{3}$ Trainees are required to adopt the lead researcher role for their major research projects, whilst being supervised by a qualified Clinical Psychologist familiar with the research methodology and/or topic area and "who is responsible for that student and for their progress and development as a researcher" (British Psychological Society [BPS $]{ }^{4}$ p. 10). Subsequently, the researcher role becomes a significant aspect of a trainee's identity throughout training. However, trainees are expected to manage a number of different professional and personal demands during training, ${ }^{5,6}$ with the

Department of Psychology and Sports Sciences, University of Hertfordshire, Hatfield, UK

\section{Corresponding author:}

Rob Brindley, Department of Psychology and Sports Sciences, University of Hertfordshire, Hatfield ALI0 9EU, UK.

Email: rob.brindley@nhs.net 
research component in particular being seen as a "difficult and demanding process" by trainees (Thomas et al., ${ }^{7}$ p.288).

This emphasis on clinical psychology trainees being adult learners and having a fairly autonomous role in regard to their thesis is not necessarily aligned with some aspects of the ethics process. In particular, although clinical psychology trainees are full-time employees of the NHS, their doctoral theses are viewed as student research within the NHS. ${ }^{8}$ In contrast to other student researchers, clinical psychology trainees are expected to have experience of audit, service evaluation and research prior to being accepted onto a training programme $\mathrm{e}^{3}$ and often have to complete a smaller research project prior to their major research project. $^{2}$ In this context, ethics committees highly recommend that research supervisors attend the committee meeting with their trainees, irrespective of the trainee's employment status or research experience. Very little is known about what this situation might be like for the trainees. Of course, some trainees might welcome having an experienced supervisor around to support them in dealing with the ethics committee. However, other trainees might feel different. They might, rightly or wrongly, feel that they are on an unequal footing in relation to other research colleagues in the NHS and the committee itself, with their skills and experience not being given sufficient consideration or acknowledgement.

In considering the role of clinical psychology and other clinical trainings within the research ethics process, a relational triad emerges between committees, courses and trainees in which differing foci and needs exist. The main priority of ethics committees is to protect participant rights within the conduct of research through themes of morality and scientific rigour, ${ }^{2,9-11}$ whilst viewing 'student research' as being difficult to carry out ethically. ${ }^{12}$ On the other hand, whilst training courses are charged with ensuring trainees develop the skills, knowledge and values necessary to conduct ethical research within clinical environments, it is also their task to support them to adopt an increasingly autonomous role within their training ${ }^{2}$ in order to prepare them for working independently as a qualified practitioner. In the training context, therefore, doctoral level students are viewed as adult learners who need to fulfil the expectations and criteria of their supervisors and courses within the specific timeframe of their training, including maintaining ethical standards in their clinical and research practice. Whilst these foci are not in conflict with each other, it could be argued that they may introduce multiple constructions of the ethics process.

At face value, Research Ethics Committees (RECs) appear to be the main, or even only, party to hold participant rights in mind. However, it has been argued that RECs embrace moral values and judgements rather than simply upholding the specific rights of participants. ${ }^{13}$ In addition, the primary focus of clinical psychology (as with other helping professions) is to alleviate distress and explore the felt experience of service users, with this being at the heart of conducted research. This is particularly true when qualitative methodologies are adopted, where the aim is to represent the participant's felt experience and voice through the study. ${ }^{14}$ Therefore, it is worth considering what each party's (ethics committee and researcher) role is in relation to the research participant. It might be useful to investigate the potential misunderstandings of each party's role and perspective in this triad and their multiple constructions of the ethics process, in the hope that this will enable these two parties to work more effectively together to improve the ethics process and therefore also the quality of doctoral level clinical research. Whilst there is a wide range of research that explores ethics principles/guidance and committee perspectives upon research ethics processes, ${ }^{9,15-19}$ there is a lack of research into trainee and student experiences of these processes. As an former trainee (RB) and course team members (LN and PN) on a Doctorate in Clinical Psychology programme in the UK, we were particularly interested in the experiences of clinical psychology trainees' experiences of engaging with the research ethics process. This study therefore aimed to investigate the first-person perspective of clinical psychology trainees who have applied for ethical approval for their clinical research projects. Such research can create a better understanding of applicants' lived experiences, in which both positive and negative experiences of the application process can be shared and explored. This understanding could help ethics committees, training courses and applicants to work together, and thus improve the application process and resulting research at a national level within the context of professional clinical training.

\section{Positional statement}

The first author's interest in exploring individuals' experiences of research ethics was borne out of his own experience of applying for NHS ethical approval for a major research project as part of his doctoral degree studies to become a Clinical Psychologist. His initial thesis project focused upon the lived experiences of young people who had sustained an Acquired Brain Injury (ABI) during their childhood and adolescence. The first author spent several months preparing an application to a local NHS REC, in which he attempted to address the need to prevent any potential harm to participants whilst emphasising the clinical, 
research and ethical need to identify these perspectives and experiences. Upon attending the REC, the first author was struck by the potential power dynamics in the room as he sat down alone at one end of a long boardroom table with the REC members sat at the other with no introductions being given. The first author attended the meeting alone, as his supervisors were unable to be there, which added to a sense of a power imbalance. The REC recommended a number of changes and that a resubmission be made, which raised anxiety for the first author around whether the project would be able to go ahead due to the timescale of his training.

After talking with his principal supervisor, time pressures meant a revised application with the recommended changes was made to another REC. The principal supervisor was able to attend this second meeting, and this time the first author had a sense of increased authority within the room. Members of the REC were introduced and were sat at a round table as a group, with the meeting feeling more of a discussion between equals. This REC provisionally accepted the application, dependent upon a number of changes being made. Some of these changes were not achievable within the timescale of the training programme, whereas others would impact upon the quality of the data being collected. Within both RECs, it was evident that the members were holding participants' best interests in mind by anticipating any potential harm. However, the first author became curious as to whether the voices and experiences of young people (i.e. the potential participants) were actually being heard and acknowledged within the research ethics process. Both the REC members and the first author were attempting to defend the rights of participants but from different perspectives.

These experiences led to the conceptualisation of the current project, in which Trainee Clinical Psychologists' felt experiences of research ethics processes were explored using qualitative methodology.

\section{Method}

\section{Participants}

Participants were recruited using purposive sampling, as the aim of the study was to develop an understanding of the lived experience of research ethics processes for doctoral students participating in clinical psychology training. Academic staff from two Doctorate in Clinical Psychology courses in the United Kingdom (one located in the South-East region and one in the North-West region) were approached to facilitate the identification of potential participants for the study. The use of two courses was decided upon to ensure that experiences were not confined to a single institution or geographical area. Potential participants were doctoral level trainee clinical psychologists in their final year of training, who had applied for ethical approval within the preceding year and who were completing their major research projects at the time. Qualified clinical psychologists who had completed their clinical training within the previous two years were also approached. Further participant characteristics are detailed in Table 1.

\section{Data collection}

Interpretive phenomenological analysis (IPA) requires a "rich, detailed first-person account of experiences" (Smith et al., ${ }^{20}$ p.56), and therefore in-depth one-toone interviews offer the most likely opportunity to capture such data. In particular, semi-structured interviews allow participants the space to "think, speak and be heard" in the context of a trusting, comfortable and bidirectional interaction (Smith et al. ${ }^{20}$ p.56). The interview schedule was initially developed by the research team and then validated through a pilot interview. The finalised interview schedule aimed to encourage the participants to talk at length via open and expansive questions, beginning with more concrete questions before moving on towards more selfreflective and analytical processes. ${ }^{20}$ It focused on the following main areas: (1) The meaning participants' attached to the phrase 'research ethics application'; (2) participants' expectations, hopes and fears of the process and whether this impacted on their choice of project; (3) participants' experiences and feelings around the application process; (4) helpful and unhelpful aspects of the process; (5) whether participants' expectations, hopes or fears were met by the process; (6) how participants' felt about applying for ethical approval in the future and (7) participants' views on what may help improve the process. The final question

Table I. Participant characteristics.

\begin{tabular}{|c|c|}
\hline $\begin{array}{l}\text { Number of } \\
\text { participants }\end{array}$ & $\begin{array}{l}\text { Seven (in line with IPA } \\
\text { methodology) }\end{array}$ \\
\hline Age & $\begin{array}{l}\text { Participants ranged in age from their } \\
\text { mid-20s to mid-30s }\end{array}$ \\
\hline Gender & All participants were female \\
\hline Nationality & All participants were UK Nationals \\
\hline Training status & $\begin{array}{l}\text { Four participants were in their final } \\
\text { year of training, with the remain- } \\
\text { ing three participants having } \\
\text { completed their training within } \\
\text { the previous two years }\end{array}$ \\
\hline $\begin{array}{l}\text { Participant pseudonyms } \\
\text { used to protect } \\
\text { anonymity }\end{array}$ & $\begin{array}{l}\text { Harriet, Britney, Jessie, Melanie, } \\
\text { Patricia, Willow and Lisa }\end{array}$ \\
\hline
\end{tabular}


focused upon the experience of being interviewed by a peer, to explore the potential impact of the shared context between the researcher and participants. This enabled participants to talk about their lived experiences and understanding of the research ethics process, including particular attention to helpful and unhelpful aspects of the process, alongside any potential changes that they would recommend being made. Formal interviews were conducted either at the participant's home, workplace or university and ranged from 60 to 110 minutes in length. Each location was chosen by individual participants to ensure their comfort and reduce any potential distress.

\section{Data analysis}

All names, places and other identifying information were modified to preserve the anonymity of the participants. IPA ${ }^{20}$ was utilised to explore the lived experiences and personal meaning-making of Trainee Clinical Psychologists' experiences of research ethics processes. IPA is an idiographic approach, and the transcripts were therefore analysed on an individual basis to allow the identification and interpretation of emergent themes to be more representative of the individual's felt experience. Transcripts were first coded and analysed by the first author, employing an interactive process, whereby the text was read repeatedly, and initial notes were made regarding the content, language, initial similarities/differences, concepts, interpretations and reflections. These initial notes were then read alongside the transcript text to identify any emergent themes. Connections between these emergent themes were then sought in order to create superordinate and underlying subordinate themes via the use of abstraction, subsumption, polarisation, contextualisation, numeration and/or function. Again, this was an interactive process in which the choice of strategies was dependent upon the specific qualities of the transcript being analysed and rereading of the text to establish whether the structure of the superordinate and subordinate themes is consistent with the participant's felt experience. Throughout this process, the anonymised transcripts and analysis notes were discussed and explored with the research team, as well as a peer support group of researchers also using IPA. Written and verbal feedback in both these contexts ensured the rigour of the analysis and helped reduce any potential impact of the first author's own experiences (as described earlier) upon the analysis. Reflexive bracketing, ${ }^{21}$ both individually and with the support of the supervising authors, was also used to consider how personal values, perspectives and experiences may influence the analytic process.

\section{Ethical considerations}

Participants were assured that their involvement in the project would in no way impact upon their job role, training and/or current research. Ethical approval for this study was provided by the School of Psychology Ethics Committees at the two universities from which participants were recruited. In addition, this research complied with the BPS Code of Human Research Ethics. $^{22}$

\section{Results}

We will discuss three main themes that were constructed from the analysis of the data: (1) The emotional intensity and personal impact of the ethics process; (2) Responses to and ways of managing the ethics process and (3) Challenges within the ethics process. Although we have attempted to separate these themes in a meaningful way from one another, we acknowledge that they are, to a certain degree, somewhat fluid and might therefore overlap with one another (thereby reflecting the intricate fabric of the participants' experience).

\section{Theme I: The emotional intensity and personal impact of the ethics process}

The experience of applying for research ethics as part of doctoral Clinical Psychology training was an emotional experience for all seven participants within this study. In particular, a sense of being overwhelmed and powerless emerged from participants' accounts, along with feelings of anxiety, isolation and relief. Jessie directly spoke of this sense of being overwhelmed, whilst struggling to find words to articulate the deep emotional meaning she ascribed to the process. She also identified distress and feeling drained as key aspects, linking them to her REC committee meeting:

This was really (exhales and pauses) anxiety provoking, just quite an overwhelming process ... particularly the ethics board...the process itself was very frustrating and very draining....it felt really quite distressing (Jessie).

A sense of isolation and potential loneliness was felt by Melanie, who named a struggle to articulate what was required of and the impact upon the self within the process. She also described how this struggle created additional pressures in her personal life:

I really struggled to explain what was going on to my family and my friends... I don't think people really understood... what it involved and the extent of it so 
they weren't able to help...they didn't understand what I was doing and couldn't quite relate to it so if anything it caused more complications... (Melanie)

Lisa appeared to hold a belief of research being her weakness, wherein a sense of powerlessness and incompetence appeared to arise out of her expectations of the gap between her own and REC members' knowledge. She then linked this with fears that others, in this case the REC, might validate her own sense of incompetence. She interpreted an unfavourable REC decision as evidence of her incompetence and this had a negative impact on her confidence:

...my experience when I went into the ethics meeting was that kind of immediate sense of feeling like... I'm just this tiny little person who doesn't sort of know anything in comparison to all these people who are gonna...tear my application apart... it felt like quite a scary process. (Lisa)

For Jessie, the REC meeting was experienced as almost a personal attack with her left feeling that she as a person is fundamentally flawed. She also describes feeling a desire and need to defend herself and her research, but feeling unable to do so and thus being pushed into a powerless position:

... at that point you come out of the meeting just thinking, oh my God there's something fundamentally wrong with me with my research and my ability to conduct research...

...it was a really frustrating and provoking and quite upsetting experience erm and I think the thing that was most difficult about it was I didn't feel like I was given the opportunity to defend it which is effectively what it felt like I was doing, I didn't feel like I was answering questions I felt like I was defending it and not just defending the work but defending myself, that it actually felt quite attacking ... (Jessie)

In contrast to many of the accounts, Britney described a largely positive experience of her REC meeting. She noted how she believed holding on to a sense of the helpfulness of the process will empower her to engage with the research ethics process in the future:

...my experience of the committee was you know quite helpful and it wasn't... like I was imagining it to be [a] grilling but it wasn't, so...that might help me in future just to think, OK let's just go for it (Britney)

\section{Theme 2: Responses to and ways of managing the ethics process}

This theme describes the range of responses to and ways of managing the ethics process identified by participants. The sense of being overwhelmed and powerless evoked strong reactions for all participants, ranging from actively wanting to avoid the process (and the emotions therein) to devaluing the process to maintain a cohesive sense of self. Searching for knowledge also emerged as a major coping strategy to increase certainty and a sense of control within the process. This search became a dilemma when engaging with peers, as they were viewed as sources of support to validate difficult emotions and experiences as well as competition to increase self-confidence and thus maintain a cohesive sense of self.

Melanie's account may hint at the underlying processes that may occur when someone views their experience of the ethics process in a negative way. She describes actively wanting to discourage others from applying for NHS ethics, immediately linking this to a battle with the process and competition with her peers. As discussed above, perhaps this hints at Melanie devaluing the process in order to make her struggles with the process more palatable. The frustration apparent within Patricia's account also hints at this function of telling negative stories:

It's made me want to say to people, to put off people doing NHS research...it's not worth it... no matter how early you try (nervous laughter) and start it's still maybe a battle so it's it seems quite quite frustrating as well that it feels a bit unfair and a bit of a lottery... And yeah that's quite hard (sounds subdued). (Melanie)

The idea of large workloads and impossible tasks as a precursor to avoidance emerged from Willow's account. She took us through her initial anxiety around an 'impossible task' and having an unknown block to completing her ethics form, perhaps not wanting to fully acknowledge the role avoidance played in her experience:

I had that form to fill in and I remember just kind of having it on the computer and just see how many pages it was but (laughs) ... I was just seeing all the different boxes that needed to be filled in and thinking I'm never gonna get this done... it just felt like an impossible task... (Willow)

Britney described a search amongst peers, supervisors and her course team for that 'magic person', who 'knew 
it all' and could guide her through the ethics process, for her to realise that person did not exist. Along with a search for practical, hands-on knowledge about the ethics process, this may have also been a desire for emotional containment ${ }^{23}$ from someone like a research supervisor. In such a contained environment, the supervisor might convey a sense of safety to the trainee, allowing them to more comfortably move through their emotions related to the ethics process.

... it would have been helpful ... if I'd had[a] supervisor who had done the research ethics before then they would have been able to help me with some of the questions that I just didn't know where to go to with... it just didn't seem a central person ... had a handle on NHS ethics. It seemed to be that even the course team [were]... not sure on the process and procedure and what would get you through committee and what wouldn't. It's just having this magic person that knew it all... (Britney)

\section{Theme 3: Challenges within the ethics process}

This final theme serves to illustrate the dilemmas and challenges participants described facing in their journeys through the ethics process. For the majority of participants, the process was experienced as an inherently complex and mysterious entity, with this uncertainty being compounded by the obstacles and time pressures they encountered. All participants spoke of a sense of the ethics committee and themselves as being in different positions and not understanding each other, wherein miscommunication and misunderstanding between both groups reinforced a 'them and us' dynamic. Finally, the impact of shared negative stories around the process upon expectations and the actual experience of the process was identified by participants, with references to these stories becoming almost folklore and being passed down from generation to generation of trainees.

This 'them and us' dynamic was most apparent in Melanie's account, in which she describes not being beaten by the REC, as if she is in a fight and the REC are actively attempting to 'knock out' her research:

... it had taken me through so many (laughing) different emotions but right at the end I felt quite kind of in control of it and empowered by it and I thought I'm not gonna let them beat me this time, I'm not gonna leave this room until they give me an approval (says quite vehemently but also laughs) so I was quite strong with it at the end. (Melanie)
For Britney, the whole process becomes a 'beast' which is holding her thesis in its mouth. This image brings up ideas around the process attempting to consume or destroy her project and potentially her dilemma of whether to engage in the fight for her research with such a daunting opponent. This transforms the ethics process literally into the other; a non-human entity:

... if you could just go to the committee and present a project, that would be fine but having to do the forms and everything else with it turns it into this beast of a thing with the thesis in its mouth. (Britney)

Patricia spoke of the pervasive nature of uncertainty within this process for her, in which they are uncertain of her role, who or where to seek guidance from and the process in general. She also named a dynamic between the time limited nature of clinical training and the 'back and forth' of research ethics, resulting in frustration and exasperation:

... at the outset it was... just utterly baffling like, what do I have to do? What are the rules? (laughs). (Patricia)

... it's just so time consuming in terms of doing a time limited project... it has to go back and forth and back and forth... doing this stupid tennis thing where they just don't have time to look at it (inhales). (Patricia)

Some participants described a wish for ethics committees to be more interested in and understanding of the specific role and experiences of trainee clinical psychologists, both in terms of strengths (e.g. experience of working with vulnerable people) and potential limitations (e.g. for some a lack of previous research experience).

... as trainees we are a quite unique group in the sense that when people ask you what you're doing in any area and you say, I'm a trainee clinical psychologist, then there's not a very good understanding of what that means and on one hand some people think you're a student, on the other hand some people think you're a clinician whereas I don't think there's a very good understanding that we're both ... so I think if there was more of a link between the trainees and the ethics committee I think that would just facilitate that understanding a bit more. (Lisa)

Britney described how the 'horror stories' she heard from other trainees placed fear into her, thus setting negative expectations around the process. Another function of these stories may be to place the difficult emotions in the other. She also spoke of being lucky, which suggests that her positive experience does not 
change her pre-conceived negative beliefs around the process:

... I came away feeling really lucky I had that particular committee meeting because I'd heard horror stories of others... it can be unhelpful that other people have such a horrible experience because then that gets sent around and it kind of puts fear into you. (Britney)

Willow described an awareness of the impact of negative stories on others, suggesting she may have edited her own 'story' due to it being shared through this study:

\begin{abstract}
... it's a bit of a balance coz you need to be able to give people advice... like, you need to make sure you start early because it is complicated and make sure you get support from other people but then you don't want to say, oh it's so awful and it's gonna completely drain all the passion for your research...(Willow)
\end{abstract}

An increased awareness of the positive aspects of her own experiences emerged for Jessie, suggesting it was easier for her to sit with the negative aspects, possibly in order to maintain a coherent sense of self:

... I possibly hadn't thought about what were the helpful aspects until it's come to today so actually having those questions asked was quite useful... (Jessie)

These accounts show the powerful impact of negative accounts on the expectations and experience of the ethics process, in which positive experiences are seen as 'lucky'. Perhaps it is easier to sit with the negative stories about the process, as the difficult emotions and feelings of incompetence are placed upon the process rather than residing within individuals. The sharing of such 'horror' stories may be an attempt to warn others not to engage with the process but was a cathartic experience for some participants. This results in a dilemma where the sharing of negative experiences is therapeutic for the storyteller, but potentially detrimental for the audience and limits the ability of positive stories to be heard.

\section{Discussion}

This qualitative study provides an original contribution to the evidence base in which post-graduate trainees' experiences of research ethics processes were explored. The use of an IPA methodology ${ }^{20}$ enabled a rich experiential account to be formed around the participants' experiences.

A pervading aspect of participants' experience was 'we were in one place and the ethics committee in another', wherein a 'them and us' dynamic emerged. Research ethics processes were construed by the majority of the participants as a repetitive and cyclical entity with inherent obstacles, barriers and time pressures, with these qualities contributing to it being seen as something to be overcome and as separate to the wider post-graduate research journey. Images of a never-ending entity of hoops and hurdles and "this beast of a thing with the thesis in its mouth" were described. These perceived barriers also contributed to the process being seen as complex, mysterious and uncertain. Participants explicitly linked uncertainty with the intense emotions they experienced, specifically being overwhelmed, anxiety, worry, frustration, selfdoubt, powerlessness and isolation. This could, for some, lead to an unhelpful avoidance or devaluing of the process.

Epstein $^{24}$ offers a possible exit strategy from this 'them and us' dynamic. The author argued that how the dominant group see individuals seeking change may be a key barrier to creating group and societal change. Within the trainee-REC dynamic, it could be argued that each system (the REC and the training programme) is dominant within their respective contexts, and thus both could be constrained by stereotypical views of the other. For example, the REC's view of doctoral research, which has been described as student research and as having very little value, ${ }^{12}$ is likely to impact on how they relate to and interact with applicants during the research meeting. Similarly, negative discourses on training programmes around negative, threatening and unpredictable or inconsistent interactions with RECs (as described in the current study) might similarly impact on applicants' responses within REC meetings. Perhaps this speaks to more locally based initiatives, in which the local RECs and training courses can build closer working relationships, for example share the training of research ethics to trainee researchers.

A contributing factor to the sense of powerlessness may be the trainee identity. Clinical Psychology employs a scientist-practitioner model, ${ }^{25}$ in which research and clinical practice are viewed as integrated rather than parallel processes. This is reflected in the doctoral training programme and the course requirement to complete a major research project. ${ }^{2}$ Despite this focus, many of the participants alluded to being more comfortable and knowledgeable about the clinician role, with research considered their 'weakness'. This sense of being a clinician rather than a researcher, and viewing them as separate entities, may come from the wider context around clinical training, in which courses express a strong desire for pre-training experience to be clinical, ${ }^{26}$ thus potentially selecting candidates who prefer direct clinical work. This highlights 
the importance for doctoral training programmes to foster a strong research identity and develop trainees' confidence in their research skills from the very start of their training. It also highlights the important role research supervisors can play in fostering research skills and confidence.

Participants responded and managed their experiences of the ethics process in several different ways. Some were 'searching for the magic person that knows it all', an impossible person who could provide knowledge, certainty, comfort and protection from their intense experiences. Others sought peer support but were faced with the dilemma of whether their peers represented support or competition. Another strategy was to devalue the ethics process, in order to displace negative emotions. The majority of participants spoke of a need for passion for the research project to sustain them through the ethics process. The cathartic nature of telling negative stories about ethics to others was described, both in the context of their experiences as well as about the interview process itself. However, such stories were also experienced as instilling negative expectations about the process, to the extent that positive stories were considered lucky even by those who had a positive experience. Again, training courses can respond to these experiences by placing the emphasis on the shared purpose (rather than the process only) of ensuring safe and ethical research and by foregrounding positive experiences of going through the ethics process.

However, it also raises the important question of why such negative experiences were recounted, with trainees describing losing confidence and their passion for their research project. It could be argued that ethics committees share some responsibility for building the next generation of health researchers with training courses. Therefore, ethics committees and their governing bodies may benefit from reflecting on the process of their meetings and consider ways that these meetings could, whilst maintaining the necessary ethical and academic rigour, also hold in mind the person of the researcher and creating a supportive environment. In particular, institutions exploring how ethics meetings may become, or maintain being, less intimidating (e.g. introducing committee members, maintaining a conversational style of communication, acknowledging existing clinical skills relevant to ethical research practices, etc.). As REC members are often unpaid volunteers, these changes in approach to chairing and managing meetings may need to be held within the trainings provided by the Health Research Authority. ${ }^{27}$ In addition, universities could create more working links and dialog with external ethics committees via trainings as well as academic staff sitting on such committees. Alongside this, Doctoral training programmes could introduce or maintain adult-learner-orientated research ethics teaching, which may be potentially useful in developing these shared values and reducing the potential for stereotyping. In saying this, we fully appreciate that such adult learning is not simply about the individual trainee and what they bring to the ethics process from their own experience. We want to be clear that we do not believe that the context of the individual trainee should be privileged at the expense of the context of maintaining appropriate ethical standards. We appreciate that, although trainees might have more clinical and research experience than many other under- and postgraduate students, the learning from this experience still needs to be tested for ethical soundness by an external body, such as an ethics committee, when a trainee wants to carry out a research project. We believe that it is possible for these two contexts to sit side-by-side, mutually influencing and complimenting one another in ways that foster high quality, ethical research.

Finally, we want to make some observations about the importance and benefits of feeling understood by the members of ethics committees. It can confirm that you are connected and 'joined up' with the committee, rather than 'cut-off' and separate from them. Feeling connected can foster a sense of working together, rather than working on one's own, to resolve ethical dilemmas. It can help to make the person feel part of the larger research community, where they are part of something larger than just being involved in their own research project. Feeling recognised and welcomed in the research community can also impact on one's professional identity. It can validate your professional sense of self, a recognition that through one's experience as a clinician you have acquired knowledge and expertise that you can usefully bring to bear on the research process, including ethical aspects of it. This external validation (and emotional containment; Bion $^{23}$ ) can, in turn, support the development of a confident and ethical researcher.

Given the qualitative nature of this study, the results cannot be readily generalised to the wider research community, and so any suggestions need to be carefully considered. Self-reflexivity of the researcher is considered an important aspect of qualitative research. ${ }^{14,20,21}$ The impact of the researcher's values, perspectives and experiences upon the analysis and interpretation of the data has been considered throughout this study. The researchers fully acknowledge that their experiences drew them towards this project, with reflexive bracketing $^{21}$ being employed to consider how their values, perspectives and experiences may have influenced the analysis process. 
It is also be important to consider the impact of participants' experiences upon the methodology of this study. As the sample were self-selected, it may be that the participants who volunteered were drawn to take part due to their intense emotional experience of the research ethics process and have a particular desire to process these difficulties within the interview process. In addition, four of the seven participants were undertaking the research projects as part of their training course requirements at the time of the interviews. Therefore, it could be argued that the current findings may be representative of a vocal minority experience. However, these experiences are still valid in considering how the process, and interaction of systems within it, impacts upon individuals within the process.

This research investigated the perspectives of one particular group using qualitative methodology. Further research could usefully investigate the experiences of other post-graduate groups via both quantitative and qualitative methods, in order to establish whether their experiences are similar or different to those of the clinical psychology trainees described in this study. Exploring the experiences of qualified or independent researchers, as well as experiences related to specific modalities or methodologies of research projects and experiences of other types of ethics committees, may help to broaden and contextualise the experiences described in the present study. It would also seem pertinent to investigate the experiences of those who sit on ethics committees, to try to obtain a broader and deeper understanding of their lived experiences of the ethics approval process. In this way, a fuller picture of the multiple perspectives of the various agents involved in the ethical approval process might well emerge. In addition, this wider exploration may also take into account the multiple epistemological stances around research ethics. Finally, further investigation of the dynamic between professionals-intraining, their training course and the RECs, as well as constructions of 'student research' within RECs, are indicated.

In conclusion, fostering confident and competent researchers within physical and mental health professions are in the interest of our national health services. Processes that may potentially discourage health practitioners from undertaking research beyond their professional training should therefore be highlighted and addressed. This study highlights some issues around the process of applying for ethical approval for clinical psychology trainees, raising important points for both training courses and ethics committees to address in order to continue to build a research active and able staff group within the NHS. The main implication of this study revolves around the importance of recognising the impact of the relationships between these groups upon trainees' journey through the research ethics process. As a result of these findings, changes to the way individuals and systems interact within the process should be considered, with the potential to improve the quality of ethics applications and subsequent research. It is the authors' hope that both positive and negative trainee experiences around ethics have been communicated.

\section{Acknowledgements}

This paper would not have been possible without the kindness and goodwill of the participants of this study. Thank you for your generosity in sharing your experiences. The authors would also like to thank Dr Louise-Margaret Conlan for her contribution to the development of this paper.

\section{Declaration of conflicting interests}

The authors declared no potential conflicts of interest with respect to the research, authorship, and/or publication of this article.

\section{Funding}

The authors received no financial support for the research, authorship, and/or publication of this article.

\section{ORCID iD}

Rob Brindley (D) https://orcid.org/0000-0002-4016-1138

\section{References}

1. Health and Care Professions Council. Standards of Education and Training Guidance. London: Health and Care Professions Council, 2017.

2. British Psychological Society. Standards for the Accreditation of Doctoral Programmes in Clinical Psychology. Leicester: British Psychological Society, 2017.

3. Clearing House for Postgraduate Courses in Clinical Psychology. Job description and person specification, www.leeds.ac.uk/chpccp/PersonSpecJobDescription.pdf (2018, accessed 28 August 2018).

4. British Psychological Society. Accreditation Through Partnership Handbook: Guidance for Clinical Psychology Programmes. Leicester: British Psychological Society, 2010.

5. Baker E. On clinical training, learning to like cabbage and how what doesn't kill you makes you stronger. Clin Psychol 2002; 14: 37-42.

6. Pica M. The ambiguous nature of clinical training and its impact on the development of student clinicians. Psychotherapy 1998; 35: 361-365.

7. Thomas GV, Turpin G and Meyer C. Clinical research under threat. Psychologist 2002; 15: 286-289.

8. National Patient Safety Agency and National Research Ethics Service. Ethical Review of Student Research: Guidance for Students, Supervisors and Research Ethics Committees. London: Department of Health, 2010. 
9. Department of Health. Report of the Ad hoc Advisory Group on the Operation of NHS Research Ethics Committees - The Warner Report. London: Department of Health, 2005.

10. Department of Health. Governance Arrangements for Research Ethics Committees: A Harmonised Edition. London: Department of Health, 2011.

11. Economic and Social Research Council. Framework for Research Ethics. Swindon: Economic and Social Research Council, 2010.

12. Tschudin V. European experiences of ethics committees. Nurs Ethics 2001; 8: 142-151.

13. Halse $\mathrm{C}$ and Honey A. Unravelling ethics: illuminating the moral dilemmas of research ethics. Signs 2005; 30: 2141-2162.

14. Elliott R, Fischer CT and Rennie DL. Evolving guidelines for publication of qualitative research studies in psychology and related fields. Br J Clin Psychol 1999; 38: 215-229.

15. Ahmed AH and Nicholson KG. Delays and diversity in the practice of local research ethics committees. $J$ Med Ethics 1996; 22: 263-266.

16. Eaton WO. Reliability in ethics reviews: some initial empirical findings. Can Psychol 1983; 24: 14-18.

17. Elliott L and Hunter D. The experiences of ethics committee members: contradictions between individuals and committees. J Med Ethics 2008; 34: 489-494.
18. Lux AL, Edwards SW and Osborne JP. Responses of local research ethics committees to a study with approval from a multicentre research ethics committee. BMJ 2000; 320: 1182-1183.

19. While AE. Research ethics committees at work: the experience of one multi-location study. $J$ Med Ethics 1996; 22: 352-355.

20. Smith JA, Flowers $\mathrm{P}$ and Larkin M. Interpretative Phenomenological Analysis: Theory, Method and Research. London: Sage Publications, 2009.

21. Ahern KJ. Pearls, pith and provocation: ten tips for reflexive bracketing. Qual Health Res 1999; 9: 457-411.

22. British Educational Research Association. Ethical Guidelines for Educational Research. London: British Educational Research Association, 2011.

23. Bion WR. Learning from Experience. London: Karnac, 1962.

24. Epstein S. Gay politics, ethnic identity: the limits of social constructionism. Socialist Rev 1987; 17: 9-54.

25. Barker C, Pistrang N and Elliott R. Research Methods in Clinical Psychology. Chichester: John Wiley, 2002.

26. Roth T. Getting on clinical training courses. Psychologist 1998; 11: 589-592.

27. Health Research Authority. REC member learning resources, www.hra.nhs.uk/planning-and-improvingresearch/learning/rec-member-learning-resources/ (2018, accessed 9 December, 2019). 